\title{
Long-Term Effect of Periodic Transcranial Direct Current Stimulation and Manual Therapy Program in Fibromyalgia Syndrome: A Case Report
}

Musa Sani Danazumi ( $\sim$ musadanazumisani@gmail.com )

College of Health Sciences, Bayero University, Kano, Nigeria https://orcid.org/0000-0002-3084-5552 Abdulsalam Mohammed Yakasai

College of Health Sciences, University of Kwazulu-Natal, Durban, South Africa https://orcid.org/00000001-8091-5443

Shehu Usman Ibrahim

College of Health Sciences, Bayero University, Kano, Nigeria

Mubarak Falke Abubakar

Federal Medical Centre, Nguru, Yobe State, Nigeria

\section{Case Report}

Keywords: Fibromyalgia syndrome, Periodic transcranial direct current stimulation, Manual therapy, Case report

Posted Date: June 25th, 2020

DOl: https://doi.org/10.21203/rs.3.rs-37517/v1

License: (9) This work is licensed under a Creative Commons Attribution 4.0 International License. Read Full License

Version of Record: A version of this preprint was published at Advances in Integrative Medicine on May 1st, 2021. See the published version at https://doi.org/10.1016/j.aimed.2020.07.014. 


\section{Abstract}

Purpose of the Study: This case report describes the management of a fibromyalgia patient using Periodic Transcranial Direct Current Stimulation (tDCS) and Manual Therapy (MT).

Materials and Methods: A 41-year-old woman presented with a complaint of generalized body pain and fatigue which started 10 years ago. The pain was associated with mood changes and insomnia among other symptoms, and was not responsive to analgesics and traditional herbal medicine. The patient was diagnosed as having FMS. Three sets of anodal tDCS for 20 minutes each with an interval of 10 minutes between successive stimulations followed by 30 minutes of MT were administered on each treatment day. The treatment was given 2 times per week for 8 weeks, totaling 16 hours of tDCS and 8 hours of MT. Outcomes were assessed at baseline (T0), at 1 (T1) and 2 months (T2) of intervention, and then at 4 (T3), 6 (T4) and 12 months (T5) of follow-up.

Results: At 12 month follow-up (T5), outcomes indicated improvement in all symptoms (WPI $=0, S S=0$, $\mathrm{FIQ}=0, \mathrm{BPI}=0, \mathrm{MFI}-20=20, \mathrm{MOS}=0, \mathrm{MASQ}=38, \mathrm{SF}-36=87, \mathrm{HADS}=3$ ).

Conclusion: Periodic tDCS followed by MT may be used to enhance long-term remission of symptoms in a patient with FMS.

\section{Introduction}

Fibromyalgia syndrome (FMS) is considered to be a chronic pain condition characterized by chronic widespread pain, fatigue, insomnia and psychological variables. ${ }^{1}$ The worldwide mean prevalence of FMS is $2.7 \%$ with females having more of the condition (4.2\%) than male counterparts $(1.4 \%){ }^{2}$ Individuals with FMS usually experience decreased quality of life, functional status, and higher utilization of healthcare system. ${ }^{3}$ No single treatment has proven effective for relieving the full range of FMS symptoms. ${ }^{4}$ In addition, randomized controlled trials of FDA approved FMS pharmaceuticals have reported considerably high number of patient drop-outs with/without adverse events which have led to so many investigations regarding what, should best be used to ameliorate FMS. ${ }^{4}$

Recently, FMS is thought to be a central pain state suggesting that while peripheral input may be playing a role, central factors (e.g., central sensitization) also likely account for much of the problem. ${ }^{5}$ In addition, abnormal firing in both central afferent and descending modulatory mechanisms contribute to

symptoms of FMS and can be targeted therapeutically with some success. ${ }^{4}$ Thus, a new approach to treatment of FMS involving transcranial direct current stimulation (tDCS) has been developed to ameliorate much more of the central symptoms. ${ }^{6}$

tDCS is a form of non-invasive brain stimulation that delivers low intensity direct current to the brain through electrodes applied directly to the skin over the target area. ${ }^{7}$ The suggested mechanisms are 
electrode dependent and involve either membrane depolarization (increased spontaneous firing and excitability of cortical neurons for anodal stimulation) or membrane hyperpolarization (decreased neuronal firing and excitability of cortical neurons for cathodal stimulation). ${ }^{6}$ In the most common procedure, one electrode is placed over a specific site, and the other reference electrode, placed in another location, completes the circuit. ${ }^{7}$ The electrode positioning ${ }^{7}$, the number of stimulation sessions and the intervals between them ${ }^{8}$ are critical in determining direction and spatial distribution of the current flow and, subsequently, the effectiveness of the treatment given. ${ }^{9}$ However, there are to date no optimal stimulation parameters for tDCS in the management of FMS (due to inherent heterogeneity among the published studies) and most studies lacked standardized reporting outcomes and are of short durations which suggest that more studies are urgently warranted. ${ }^{6}$

Although tDCS may be used to manage central symptoms in FMS, other peripheral symptoms such as myofascial dysfunctions and/or bony imbalances may better be managed using manual therapy and should not be ignored. ${ }^{10}$ In addition, the main symptom which guides patient's health seeking behavior is muscle pain and localized treatments such as soft tissue manual therapies are usually sought. ${ }^{11}$ Moreover, evidence for the positive effects of soft tissue manual therapy in the management of FMS has been reported by a recent systematic review. ${ }^{12}$ Furthermore, a previous study ${ }^{13}$ also indicated that if tDCS is used in combination with manual therapy in the management of FMS longer and better treatment effects may be enhanced.

FMS is a chronic state involving a wide variety of symptoms and to manage it to achieve maximum and long-term remission of symptoms, a combination of therapeutic interventions may likely be used during the rehabilitation program. ${ }^{13}$ This current study reported the long-term effects of periodic tDCS and manual therapy in the management of a patient with FMS, utilizing standardized reporting outcomes recommended by the working group within Outcome Measures in Rheumatology (OMERACT). ${ }^{1}$

\section{Case Presentation}

\subsection{Case}

The patient was a 41-year-old civil servant who was referred to the Physiotherapy Department of Federal Medical Center (FMC) Nguru, Yobe State, Nigeria, with a complaint of generalized body pain (see Table 1 for patient's demographics). The pain started 10 years ago and increased gradually. The pain was worst in the morning and at night during rest. The patient had associated the pain with generalized body fatigue, insomnia, and stiffness of the extremities with mood changes usually coming up whenever the patient was not at work. The patient had no trauma or systemic problem in her clinical past but reported frequent taking medications than prescribed to ease the pain and had considerably added weight because of inactivity. In January 2014, the patient underwent liver function tests (LFTs) and urinalysis following a complaint of right lower abdominal pain and swelling that were severe upon lying on the ipsilateral side. Despite the fact that all the clinical tests were negative, physical examination indicated 
tightness of the external oblique and hypertrophy of the quadratus lumborum on the ipsilateral side and the patient was treated. Two years later (after January 2014), the patient presented to the General Outpatient Department (GOPD) of our hospital, with a complaint of generalized body pain and fatigue that were not responsive to analgesics and traditional herbal medicine. The patient was diagnosed as having chronic non-specific low back pain and was placed on medications, exercises and diet for 6 months which were later extended to 12 months. After 12 months of treatment with the GOPD, the attending physician noticed that the patient's condition has deteriorated and was therefore asked to suspend all previous treatments and then referred to physiotherapy department for further evaluation and treatment.

Table 1: Patient's Demographics

\begin{tabular}{ll}
\hline Characteristics & \\
\hline Gender & Female \\
Age & 41 \\
\hline Weight & $80 \mathrm{~kg}$ \\
\hline Height & $1.5 \mathrm{~m}$ \\
\hline BMI & $35.56 \mathrm{~kg} / \mathrm{m}^{2}$ \\
\hline Duration of symptoms & 10 years \\
\hline
\end{tabular}

BMI=Body mass index

\subsection{Assessment and Diagnosis}

Upon arrival to physiotherapy, thorough pathological and hematological examinations were conducted and the results were normal as were examinations of the lumbosacral and cervical spines through plain radiographs (to rule out spinal pathologies that may cause pain and/or radiate pain to the extremities). In addition, other clinical tests such as LFT and urinalysis did not reveal any significant biomarker suggesting other commobidities. However, physical assessment of the patient revealed active trigger points (TrPs) around the neck muscles especially the sternocleidomastoid (SCM), scalenes and suboccipital muscles with radiating pain to the bilateral arms. The superficial back line (SBL) was tight and painful with more TrPs around the erector spinae, piriformis and lower harmstrings bilaterally. The superficial frontal line (SFL) was stretched out with more TrPs around the lower abdominals, hip flexors and quadriceps on both sides. Further assessment revealed tightness of the lateral line (LL) with active TrPs around the intercostals, quadratus lumborum and iliotibial band (ITB) on both sides. Bony palpation indicated bilateral fixation of T4 vertebra (fixed open-locked in flexion) with radiating pain to the neck and shoulders. The widespread pain index (WPI) ${ }^{14}$ was 16 (0-19 scores, 4-point reduction indicates a clinically meaningful change) ${ }^{15}$ and the symptom severity scale (SSS) ${ }^{14}$ scores of the patient was 8 (0- 
12 scores, 3-point reduction indicates a clinically meaningful change). ${ }^{15}$ Other outcomes including Fibromyalgia Impact Questionnaire (FIQ) ${ }^{16}$ - used to measure total spectrum of problems related to fibromyalgia and associated responses to therapy (0-100 scores, $14 \%$ reduction represents a clinically meaningful change) ${ }^{17}$; Brief Pain Inventory (BPI) ${ }^{18}$ — used to measure pain (0-10 scores, $30 \%$ reduction represents a clinically meaningful change $)^{19}$; Multidimensional Fatigue Inventory-20 (MFI-20) ${ }^{20}$ — used to measure fatigue (20-100 scores, clinically meaningful change for FMS not established) ${ }^{21}$; Medical Outcomes Study Sleep Scale (MOS) 22 —used to measure sleep disturbance (0-100 scores, 7.9-point reduction represents a minimum important difference) ${ }^{23}$; Multiple Ability Self-Report Questionnaire $(\mathrm{MASQ})^{24}$ - used to measure cognitive dysfunction (38-190 scores, clinically meaningful change for FMS not established) ${ }^{21}$; Hospital Anxiety and Depression Scale (HADS) ${ }^{25}$ _ used to measure mood (0-14 scores, clinically meaningful change for FMS not established) ${ }^{21}$; and Short Form Health Survey Questionnaire (SF-36) ${ }^{26}$ —used to measure quality of life (0-100 scores, 6-point increase represents a clinically meaningful change $)^{21}$; recommended by the working group within the OMERACT ${ }^{1}$, were also used to assess the patient's clinical presentations at baseline (T0), at 1 (T1) and 2 month (T2) of treatment, and after 4 (T3), 6 (T4) and 12 month (T5) of follow-up (see Table 2). The patient was diagnosed by a team of orthopedic physiotherapists and family physicians as having fibromyalgia syndrome. The diagnosis was based on the American College of Rheumatology (ACR) criteria. ${ }^{27}$

\subsection{Treatment of the Patient}

\subsubsection{Rationale for the new treatment}

Ordinarily, tDCS application in the management of FMS has only been long-interval (wider/single stimulation per visit) and has never been periodic (repeated circles at short intervals per visit). The therapeutic effect of the long-interval stimulation has however, been observed to be short lived. ${ }^{28}$ This set back in the efficacy of long-interval tDCS has been attributed to the fact that widely spaced stimulation activates $\mathrm{Ca}^{2+} /$ calmodulin-dependent kinases (CaMKs) through increase in post-synaptic calcium concentration ${ }^{29}$ which maintain their activity through auto-phosphorylation for some time before the calcium gets depleted through the process of synaptic homeostasis and thus, the short-term improvement following the widely spaced tDCS in most fibromyalgia clinical trials. ${ }^{30}$

On the other hand, periodic tDCS which has never being studied except in this current case report is believed to induce long-term remission of symptoms of FMS. This belief was supported by the pertinent literature. Firstly, a previous study by Reymann and Frey ${ }^{31}$ indicated that late long-term potentiation (ILTP) occurred in individuals following tDCS application, if two or more stimulation sessions within a critical time window of about 30 minutes after the first stimulation were given. Secondly, another study by Monte-Silver and colleagues ${ }^{28}$ indicated that I-LTP like excitability enhancements in the primary motor cortex of healthy subjects were induced by giving two sessions of spaced tDCS with short interval of 3 or 20 minutes in-between, which was present for more than 24 hours after tDCS and these were seen to have abolished when a wide interval of 3 or 24 hours was used. In addition, studies by Kornell and Co- 
workers $^{32}$, and Overduin and colleagues ${ }^{33}$ on learning and memory have also supported this belief in which they reported that low number of repetitions with short intervals in-between are better in the longterm memory formation.

Even though tDCS can be used to manage most of the central symptoms in FMS, other peripheral symptoms such as myofascial dysfunctions should not be overlooked. ${ }^{10}$ However, peripheral symptoms in FMS are quite generic and to abolish them symptom-specific manual therapy techniques may be employed. ${ }^{11}$ In addition, the benefit of using tDCS combined with manual therapy has been indicated by a previous study ${ }^{13}$ which reported that tDCS application may act as a facilitator of behavioral modifications (undesirable behaviors are replaced with more desirable ones through the process of positive reinforcement) by establishing a favorable neural environment if all the stimulations were performed before the first hour of manual therapy.

\subsection{2 tDCS Application}

The patient was managed using anodal tDCS with the anode electrode placed on the left primary motor cortex (left-M1) at C3, while the cathode was placed on the contralateral supraorbital region. The site of the stimulation was determined using 10-20 international EEG system of electrode placement. ${ }^{34}$ The stimulation protocol reported in the previous systematic review ${ }^{6}$ consisting of $2 \mathrm{~mA}$ stimulation for 20 minutes was used. However, because of the aim of the study of inducing long-term remission of symptoms, 3 series of stimulations for 20 minutes each with an interval of 10 minutes between successive stimulations were given on each treatment day. The treatment was given 2 times per week for 8 weeks.

\subsubsection{Manual Therapy_Application}

Manual therapy program was also administered to the patient. Just like the tDCS, the manual therapy program was also given 2 times per week for 8 weeks. The manual therapy program that was used in this study involved a combination of soft-tissue spinal manipulative therapy (SMT), positional release techniques (PRTs), integrated neuromuscular inhibition techniques (INIT), neuromuscular techniques (NMTs) and progressive inhibition of neuromuscular structures (PINS). However, each manual therapy program was dependent on the patient's specific clinical presentation and physical assessment outcomes because the patient had a widespread body pain. The SMT was performed to release the facet joint fixation at T4 vertebra, INIT was performed to ameliorate piriformis pain, PRT was used to deactivate TrPs at the SCM, scalenes and sub-occipital muscles, NMTs were used to abolish intercostals and lower abdominal muscles pains, and PINS was used to deactivate multiple TrPs at the ITB and hamstrings. Each manual therapy session lasted for 30 minutes. The full description of each manual therapy technique can be found below:

- Spinal manipulative therapy (SMT): Maitland's protocol ${ }^{35}$ of releasing bilateral facet joint fixation was used. The patient was in the sitting position, the physiotherapist (PT) then placed the knuckle of 
his right forefinger in the right spinal groove and the knuckle of his left forefinger in the left spinal groove. Because the PT was dealing with bilaterally fixed open facets, the patients was asked to back bend over the knuckles of the PT as he applied pressure to both sides and wait for the release.

- Positional release techniques (PRTS): As the painful point was located which could be a 'tender' point, or an actual trigger point, sufficient pressure is applied to the point to cause some pain. If it was a trigger point enough pressure was applied to cause the referred symptoms and then the patient was told to give the pain being felt a value of ' 10 '. A fine tuning was applied to position the area in such a way as to lessen the pain from the point because creating 'ease' in the tissues housing the point usually involves producing some degree of increased slack in the palpated tissues. This position was held for 90 seconds or until pain diminished and then the site was slowly returned to the neutral position and re-palpated. ${ }^{36}$

- Integrated neuromuscular inhibition techniques (INIT): The trigger point was first identified by palpation and then ischemic compression was applied in either a sustained or intermittent manner to lessen the pain. When referred or local pain started to reduce in intensity, the compression treatment stopped and then the patient was instructed to use no more than $20 \%$ of available strength to attempt to take the limb away from the restriction barrier, while the PT held the limb firmly to create isometric contraction which was maintained for 7 to 10 seconds. ${ }^{37}$

- Neuromuscular techniques (NMTs): Depending on the body regions being treated, the PT utilized the thumb or index or middle finger, supported by the neighboring digits to palpate and assess the tissues for local dysfunction. Body regions such as intercostals muscles were treated using fingers because the thumb could not maintain the required pressure for strokes. In the NMT thumb technique, the fingers of the treating hand acted as a fulcrum (remained stationary) and that they lied at the front of the contact, allowing the stroke made by the thumb to run across the palm of the hand, towards the ring or small finger as the stroke progresses for approximately $4-5 \mathrm{~cm}$ before the thumb ceases its motion, at which time the fulcrum/ fingers can be moved further ahead in the direction the thumb needed to travel. ${ }^{38}$ For areas having multiple TrPs along a continuum such as the ITB and hamstrings, PINS was used to abolish the pain. ${ }^{39}$

- Progressive inhibition of neuromuscular structures (PINS): This technique was performed by palpating two related points termed primary point and secondary or end point. Primary and end points are areas of most and least sensitivity respectively found along the continuum of a neuromuscular structure. In this technique, moderate ischemic compression was steadily maintained on the end point by the use of index finger of the left hand without relieving pressure up to the completion of the technique. The index finger of the right hand applied pressure on the primary point for about 30 seconds after which another sensitive point was palpated by the middle finger of same hand proximal to the end point without relieving pressure on index finger. If the patient indicated that this latter point was more sensitive than the posterior point, then pressure was maintained on the second point and relieved on the first point without relieving the end point pressure. This was maintained for 30 seconds before the third point was identified. If the third point was identified as more sensitive than the second point, then pressure was relieved from the second point and 
maintained on the third point for another 30 seconds. The same pattern was followed progressively along the dysfunctional neuromuscular structure until the last point approximately $2 \mathrm{~cm}$ proximal to the end point was found. Pressure was maintained for 30 seconds simultaneously on the two points (the last point and the end point) and then relieved. ${ }^{40}$

\subsection{Progress and Results}

Outcomes were measured at baseline (T0) and at 1 (T1) and 2 (T2) months of intervention. The patient was discharged home after 2 months of intervention and placed on therapeutic exercises as home regimen. ${ }^{39}$ The patient was then followed-up (through physical visits) to a year to track improvement in symptoms (see Figure 1 for participant's flow through the study). At 6 month follow-up (T4), the outcomes indicated improvement in all symptoms (WPI=0, SS $=0, F I Q=10, B P I=0, M F I-20=20, M O S=0$, $M A S Q=38, S F-36=87$ ), with the exception of $\operatorname{mood}(H A D S=7)$ which was found to have fluctuated. However, at 12 month follow-up (T5), improvement in all outcomes (including the mood) was maintained $(\mathrm{WPI}=0, \mathrm{SS}=0, \mathrm{FIQ}=0, \mathrm{BPI}=0, \mathrm{MFI}-20=20, \mathrm{MOS}=0, \mathrm{MASQ}=38, \mathrm{SF}-36=87, \mathrm{HADS}=3$ ) (see Table 2 and Figures $2 \& 3)$.

\section{Table 2: Results}

\begin{tabular}{ccccccc}
\hline Outcomes & T0 & T1 & T2 & T3 & T4 & T5 \\
\hline WPI (0-19) & 16 & 7 & 5 & 2 & 0 & 0 \\
SSS (0-12) & 8 & 4 & 2 & 0 & 0 & 0 \\
\hline FIQ (0-100) & 80 & 50 & 25 & 10 & 10 & 0 \\
\hline BPI (0-100) & 76 & 60 & 28 & 0 & 0 & 0 \\
\hline MFI-20 (20-100) & 65 & 48 & 35 & 20 & 20 & 20 \\
\hline MOS (0-100) & 80 & 30 & 0 & 0 & 0 & 0 \\
\hline MASQ (38-190) & 138 & 84 & 68 & 45 & 38 & 38 \\
\hline SF-36 (0-100) & 18 & 35 & 56 & 87 & 87 & 87 \\
\hline HADS (0-14) & 14 & 9 & 3 & 3 & 7 & 3 \\
\hline
\end{tabular}

Key: Lower scores indicate improvement in all outcomes with the exception of SF-36 in which lower scores indicate worsening symptoms; WSP=Widespread Pain Index; SS=Severity Scale; FIQ=Fibromyalgia Impact Questionnaire; BPI=Brief Pain Inventory; MFI-20=Multidimensional Fatigue Inventory (MFI-20); MOS=Medical Outcomes Study Sleep Scale; MASQ=Multiple Ability Self-Report Questionnaire; HADS=Hospital Anxiety and Depression Scale; SF-36=Short Form Health Survey; T0=Outcomes at baseline; T1=Outcomes at 1-month; T2=Outcomes at 2-months; T3=Outcomes at 4-months; T4=Outcomes at 6-months; T5=Outcomes at 12-months.

\section{Discussion}


Fibromyalgia syndrome is currently considered to be one of the most difficult conditions to manage to both rheumatologists and somatic healthcare professionals worldwide. ${ }^{12}$ Given that the condition has central sensitization components, tDCS may be a useful intervention for some patients. ${ }^{6}$ However, there are no optimal stimulation parameters for tDCS and most of the published studies lacked standardized reporting outcomes and are of short durations. ${ }^{6}$ Even though tDCS can be used to manage central symptoms in FMS, other peripheral symptoms may better be managed using manual. ${ }^{12}$ The benefit of using tDCS combined with manual therapy has been previously reported. ${ }^{17}$

This current study investigated the long-term effects of periodic tDCS followed by symptom-specific manual therapy techniques in the management of a patient with FMS. The findings of the study indicated improvement in all symptoms after 12-months follow-up. The improvement in symptoms seen in this study may be partly explained by the induction of I-LTP following tDCS application. I-LTP is the excitability enhancement lasting for more than 3 hours due to sustained activity of CaMKs and subsequent activation of transcription factors, gene expression and protein synthesis to accomplish permanent alteration in synaptic strength. ${ }^{30}$ On the other hand, the improvement seen may also be explained by the facilitatory effects of tDCS in behavioral modifications thereby establishing a favorable neural environment because all the stimulations were performed before the first hour of manual therapy. ${ }^{13}$

In this current study, several sessions of periodic tDCS and manual therapy administered to the patient were found to induce long-term remission of symptoms of FMS. The effects achieved may also be attributed to the fact that gene transcription does not occur immediately as it takes sometimes to commence. ${ }^{31}$ In addition, since I-LTP is the molecular mechanism behind learning and memory, the phenomenon that memory consolidation takes place during deep sleep might have contributed to the long lasting improvement of symptoms achieved in the study. ${ }^{24,25}$ However, mood outcome had been observed to have fluctuated after 6 months of follow-up and this had led the research team to further invite the patient for one-on-one discussion. Upon discussion it was learnt that the patient was in her menstruation period and that could have possibly been the reason why she had mood fluctuation during the $6^{\text {th }}$ month of follow-up.

\section{Conclusion}

Repeated circles of tDCS occurring at regular intervals followed by manual therapy program may be used to enhance long-term remission of symptoms in individuals with FMS. This is the first report of a fibromyalgia patient managed using periodic tDCS and evaluated using standardized reporting outcomes. The outcomes of this case report cannot be generalizable and it is recommended that cohort studies may first be conducted before progression to randomized controlled trials to establish the efficacy of these current findings. In addition, it is also recommended that an optimal number of standardized patient-reported outcome measures and optimal doses of the interventions should also be reported in future studies to allow equivalence of data and clinical decision making. 
Clinical Relevance: This study highlighted for the first time the significance of using periodic tDCS in the management of FMS. The study also highlighted the need for using standardized outcome measures in FMS research.

Adverse Effect: The patient did not report any other side-effects apart from the known side effect of tDCS (mild itching at the beginning of the stimulation which became abolished within few seconds).

\section{Declarations}

Research Funding: This study did not receive any funding.

Conflict of Interest: No conflict of interest declared.

Informed Consent: The patient was informed that participation in the study was voluntary and that she could withdraw from the study at any time without the care being compromised in any way.

\section{CONSENT STATEMENT:}

The patient has signed informed consent and agreed for the study to be published. In addition, the patient was assured that her anonymity would be maintained and she has the right to withdraw from the study at any point in time without her treatment being impeded.

\section{References}

1. Mease PJ, Arnold LM, Crofford LJ, Williams DA, Russell IJ, Humphrey L, et al. Identifying the clinical domains of fibromyalgia: Contributions from clinician and patient delphi exercises. Arthritis Rheum [Internet]. 2008 Jul 15 [cited 2019 May 16];59(7):952-60. Available from: http://www.ncbi.nlm.nih.gov/pubmed/18576290.

2. Queiroz LP. Worldwide Epidemiology of Fibromyalgia. Curr Pain Headache Rep [Internet]. 2013 Aug 26 [cited 2019 May 16];17(8):356. Available from: http://www.ncbi.nlm.nih.gov/pubmed/23801009.

3. Berger A, Dukes E, Martin S, Edelsberg J, Oster G. Characteristics and healthcare costs of patients with fibromyalgia syndrome. Int J Clin Pract [Internet]. 2007 Jul 26 [cited 2019 May 16];61(9):1498508. Available from: http://doi.wiley.com/10.1111/j.1742-1241.2007.01480.x

4. Häuser W, Bernardy K, Üçeyler N, Sommer C. Treatment of fibromyalgia syndrome with gabapentin and pregabalin - A meta-analysis of randomized controlled trials. Pain [Internet]. 2009 Sep [cited 2019 May 16];145(1):69-81. Available from: http://www.ncbi.nlm.nih.gov/pubmed/19539427

5. Clauw DJ. Fibromyalgia. JAMA [Internet]. 2014 Apr 16 [cited 2019 May 16];311(15):1547.Availablefrom:http://jama.jamanetwork.com/article.aspx? doi=10.1001/jama.2014.3266.

6. Marlow NM, Bonilha HS, Short EB. Efficacy of Transcranial Direct Current Stimulation and Repetitive Transcranial Magnetic Stimulation for Treating Fibromyalgia Syndrome: A Systematic Review. Pain 
Pract [Internet]. 2013 Feb [cited 2019 May 16];13(2):131-45. Available from:

http://doi.wiley.com/10.1111/j.1533-2500.2012.00562.x.

7. Rosen AC, Ramkumar M, Nguyen T, Hoeft F. Noninvasive transcranial brain stimulation and pain. Curr Pain Headache Rep [Internet]. 2009 Feb [cited 2019 Aug 4];13(1):12-7. Available from: http://www.ncbi.nlm.nih.gov/pubmed/19126365.

8. Reymann KG, Frey JU. The late maintenance of hippocampal LTP: Requirements, phases, 'synaptic tagging', 'late-associativity' and implications. Neuropharmacology [Internet]. 2007 Jan [cited 2019 May 16];52(1):24-40. Available from: http://www.ncbi.nlm.nih.gov/pubmed/16919684.

9. Utz KS, Dimova V, Oppenländer K, Kerkhoff G. Electrified minds: Transcranial direct current stimulation (tDCS) and Galvanic Vestibular Stimulation (GVS) as methods of non-invasive brain stimulation in neuropsychology-A review of current data and future implications. Neuropsychologia [Internet]. 2010 Aug [cited 2019 Aug 4];48(10):2789-810. Available from:

http://www.ncbi.nlm.nih.gov/pubmed/20542047.

10. Staud, R. Peripheral Pain Mechanisms in Chronic Widespread Pain. Best Practice \& Research: Clinical Rheumatology. 2011; 25(2): 155-164. doi:10.1016/j.berh.2010.01.010.

11. Wahner-Roedler DL, Vincent A, Mandrekar JN, Thompson JM, Oh TH, Loehrer LL, Elkin PL, Bauer BA. Use of Complementary and Alternative Medical Therapies by Patients Referred to a Fibromyalgia Treatment Program at a Tertiary Care Center. Mayo Clin. Proc. 2005; 80, 55-60. https://doi.org/10.4065/80.1.55.

12. Sturman S, Killingback C. Is There a Dose Response Relationship Between Soft Tissue Manual Therapy and Clinical Outcomes in Fibromyalgia?, Journal of Bodywork \& Movement Therapies. 2020. https://doi.org/10.1016/j.jbmt.2020.02.010.

13. Riberto M. Efficacy of Transcranial Direct Current Stimulation Coupled with a Multidisciplinary Rehabilitation Program for the Treatment of Fibromyalgia. The Open Rheumatology Journal. 2011; 5(1), pp.45-50. Available at: http://www.ncbi.nlm.nih.gov/pubmed/22046206 [Accessed May 16, 2019].

14. Wolfe F, Clauw DJ, Fitzcharles M-A, Goldenberg DL, Katz RS, Mease P, et al. The American College of Rheumatology Preliminary Diagnostic Criteria for Fibromyalgia and Measurement of Symptom Severity. Arthritis Care Res (Hoboken) [Internet]. 2010 Feb 23 [cited 2019 May 16];62(5):600-10. Available from: http://www.ncbi.nlm.nih.gov/pubmed/20461783.

15. Wolfe F, Egloff N, Häuser W. Widespread Pain and Low Widespread Pain Index Scores among Fibromyalgia-positive Cases Assessed with the 2010/2011 Fibromyalgia Criteria. The Journal of Rheumatology. 2016; 43:9;doi:10.3899/jrheum.160153.

16. Bennett RM. The Fibromyalgia Impact Questionnaire (FIQ): a review of its development, current version, operating characteristics and uses. Clin Exp Rheumatol 2005;23:S154 62.

17. Bennett RM, Bushmakin AG, Cappelleri JC, Zlateva G, Sadosky AB. Minimal clinically important difference in the fibromyalgia impact questionnaire. J Rheumatol. 2009;36:1304-11. 
18. Tan G, Jensen MP, Thornby JI, Shanti BF. Validation of the Brief Pain Inventory for chronic nonmalignant pain. J Pain. 2004;5:133-7.

19. Farrar JT, Portenoy RK, Berlin JA, Kinman JL, Strom BL. Defining the clinically important difference in pain outcome measures. Pain. 2000; 88:287-94.

20. Smets EM, Garssen B, Bonke B, De Haes JC. The Multidimensional Fatigue Inventory (MFI) psychometric qualities of an instrument to assess fatigue. J Psychosom Res 1995;39:315-25.

21. Williams DA, Arnold LM. Fibromyalgia Impact Questionnaire (FIQ), Brief Pain Inventory (BPI), Multidimensional Fatigue Inventory (MFI-20), Medical Outcomes Study (MOS) Sleep Scale, and Multiple Ability Self-Report Questionnaire (MASQ). Arthritis Care \& Research. 2011; 63(11), S86-S97. Doi: 10.1002/acr.20531.

22. MOS: Martin S, Chandran A, Zografos L, Zlateva G. Evaluation of the impact of fibromyalgia on patients' sleep and the content validity of two sleep scales. Health Qual Life Outcomes 2009;7:64.

23. Cappelleri JC, Bushmakin AG, McDermott AM, Dukes E, Sadosky A, Petrie CD, et al. Measurement properties of the Medical Outcomes Study Sleep Scale in patients with fibromyalgia. Sleep Med 2009;10: 766-70.

24. Williams DA, Clauw DJ, Glass JM. Perceived cognitive dysfunction in fibromyalgia syndrome. J Musculoskelet Pain 2011;19:66-75.

25. Zigmond AS, Snaith RP. Acta psychiatrica scandinavica. Hosp Anxiety Depression Scale. 1983;67(6):361-370.

26. Hoffman DL, Dukes EM. The health status burden of people with fibromyalgia: a review of studies that assessed health status with the SF-36 or the SF-12. Int J Clin Pract. 2008; 62(1): 115-126. doi: 1111/j.1742-1241.2007.01638.x.

27. Wolfe F, Clauw DJ, Fitzcharles M, Goldenberg DL, Häuser W, Katz RL, Mease PJ, Russell AS, Russell JI, Walitt B, 2016 Revisions to the 2010/2011 Fibromyalgia Diagnostic Criteria2016 Revised Fibromyalgia Criteria, Seminars in Arthritis and Rheumatism. 2006. http://dx.doi.org/10.1016/j.semarthrit.2016.08.012.

28. Monte-Silva K, Kuo M-F, Hessenthaler S, Fresnoza S, Liebetanz D, Paulus W, et al. Induction of Late LTP-Like Plasticity in the Human Motor Cortex by Repeated Non-Invasive Brain Stimulation. Brain Stimul [Internet]. 2013 May [cited 2019 May 16];6(3):424-32. Available from: http://www.ncbi.nlm.nih.gov/pubmed/22695026.

29. Romcy-Pereira R, Pavlides C. Distinct modulatory effects of sleep on the maintenance of hippocampal and medial prefrontal cortex LTP. Eur J Neurosci [Internet]. 2004 Dec [cited 2019 May 16];20(12):3453-62. Available from: http://www.ncbi.nlm.nih.gov/pubmed/15610178.

30. Nitsche MA, Fricke K, Henschke U, Schlitterlau A, Liebetanz D, Lang N, et al. Pharmacological Modulation of Cortical Excitability Shifts Induced by Transcranial Direct Current Stimulation in Humans. J Physiol [Internet]. 2003 Nov 15 [cited 2019 May 16];553(1):293-301. Available from: http://www.ncbi.nlm.nih.gov/pubmed/12949224. 
31. Reymann KG, Frey JU. The late maintenance of hippocampal LTP: Requirements, phases, 'synaptic tagging', 'late-associativity' and implications. Neuropharmacology [Internet]. 2007 Jan [cited 2019 May 16];52(1):24-40. Available from: http://www.ncbi.nlm.nih.gov/pubmed/16919684.

32. Kornell N, Castel AD, Eich TS, Bjork RA. Spacing as the friend of both memory and induction in young and older adults. Psychol Aging [Internet]. 2010 Jun [cited 2019 May 16];25(2):498-503. Available from: http://www.ncbi.nlm.nih.gov/pubmed/20545435.

33. Overduin SA, Richardson AG, Lane CE, Bizzi E, Press DZ. Intermittent Practice Facilitates Stable Motor Memories. J Neurosci [Internet]. 2006 Nov 15 [cited 2019 May 16];26(46):11888-92. Available from: http://www.ncbi.nlm.nih.gov/pubmed/17108162.

34. Rich T, Gillick B. Electrode Placement in Transcranial Direct Current Stimulation-How Reliable Is the Determination of C3/C4? Brain Sciences. 2019. 9(3), p.69. Available at: http://www.ncbi.nIm.nih.gov/pubmed/30909374 [Accessed May 16, 2019].

35. Maitland J. Spinal manipulation made simple: a manual of soft tissue techniques. $1^{\text {st }} 2001$. Berkeley, California, USA: North Atlantic Books.

36. Chaitow L. Positional Release Techniques. $4^{\text {th }} 2014$. London, UK: Churchill Livingstone.

37. Danazumi M S, Yakasai A M, Ibrahim S U. Effect of Integrated Neuromuscular Inhibition Technique in the Management of Piriformis Syndrome: A Case Report. Middle East J Rehabil Health Stud. 2020. Online ahead of Print ; 7(2):e101764. doi: 10.5812/mejrh.101764.

38. Chaitow L. Modern Neuromuscular Techniques ( $4^{\text {th }}$ edition). 2010. Churchill Livingstone, Edinburgh.

39. Danazumi MS., Ibrahim SU. Effectiveness of Progressive Inhibition of Neuromuscular Structures and Spinal Mobilization with Leg Movement in Lumbar Disk Herniation with Radiculopathy: A Case Report with Two Year Follow-up. IJSRP. 2019; 9(1), 313-318. DOI: http://dx.doi.org/10.29322/IJSRP.9.01.2019.p8542.

40. Dowling DJ. Progressive Inhibition of Neuromuscular Structures Techniques. In DiGiovanna, Eileen L. An Osteopathic Approach to Diagnosis and Treatment, $3^{\text {rd }}$ Philadelphia, PA: Lippincott, Williams \& Wilkins: 2005:118-122, 158-160, 346-348.

41. Xue, G. Mei L, Chen C, Lu ZL, Poldrack R, Dong Q. Spaced Learning Enhances Subsequent Recognition Memory by Reducing Neural Repetition Suppression. Journal of Cognitive Neuroscience. 2011. 23(7), pp.1624-1633. Available at: http://www.ncbi.nlm.nih.gov/pubmed/20617892 [Accessed May 16, 2019].

42. Ravassard P, Pachoud B, Comte JC, Mejia-Perez C, Scoté-Blachon C, Gay N, Claustrat B, Touret M, Luppi PH, Salin PA. Paradoxical (REM) Sleep Deprivation Causes a Large and Rapidly Reversible Decrease in Long-Term Potentiation, Synaptic Transmission, Glutamate Receptor Protein Levels, and ERK/MAPK Activation in the Dorsal Hippocampus. Sleep. 2009. 32(2), pp.227-240. Available at: http://www.ncbi.nlm.nih.gov/pubmed/19238810.

\section{Figures}




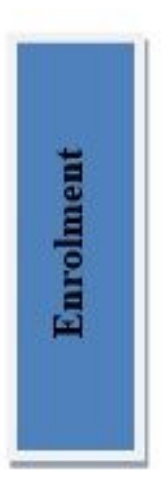

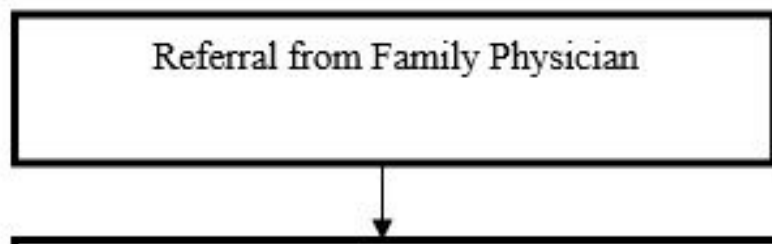

Assessment and Diagnosis (including

completion of baseline questionnaires)
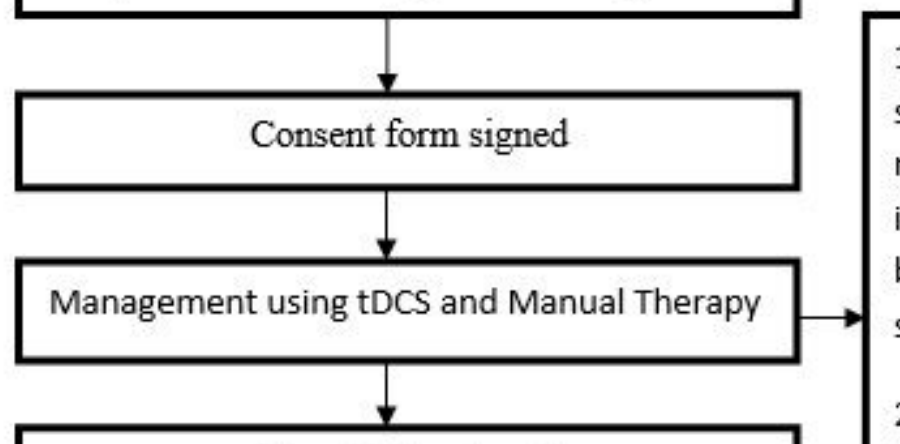

4 weeks treatment

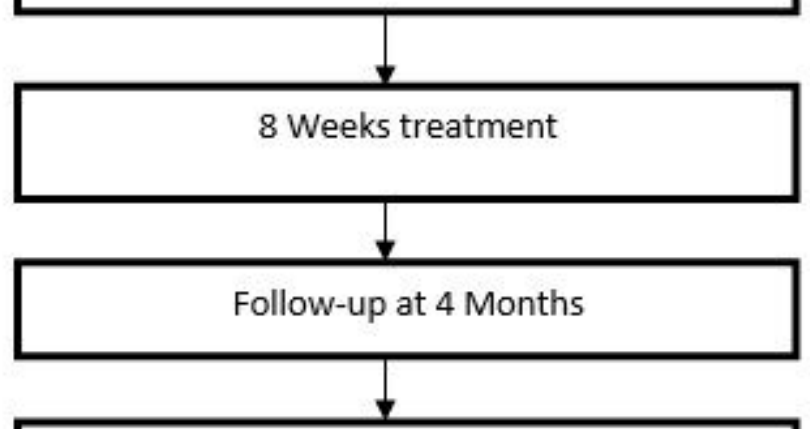

Follow-up at 6 Months

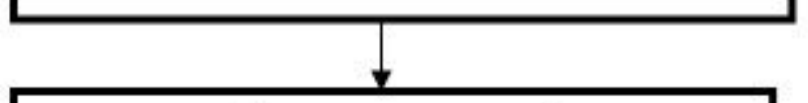

Follow-up at 12 Months

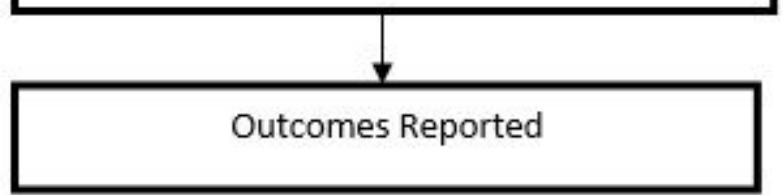

1) 3 series of tDCS

stimulations for 20

min each with an

interval of $10 \mathrm{~min}$

between successive

stimulations.

2) Symptom-specific

Manual Therapy

Techniques.

\section{Figure 1}

Participant's flow through the study 


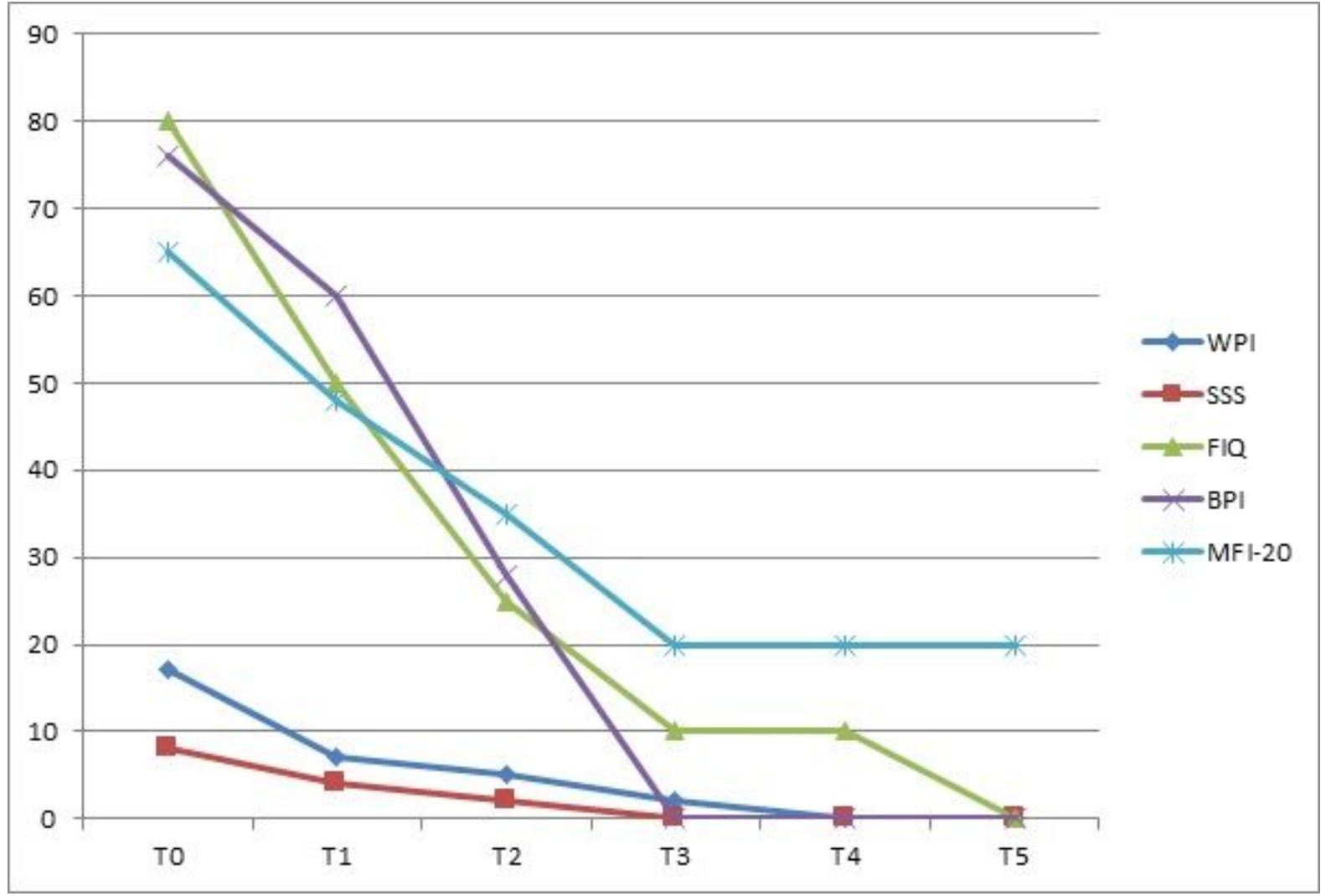

Figure 2

Line graph showing trend in the outcomes (WPI, SSS, FIQ, BPI \& MFI-20) across timeline

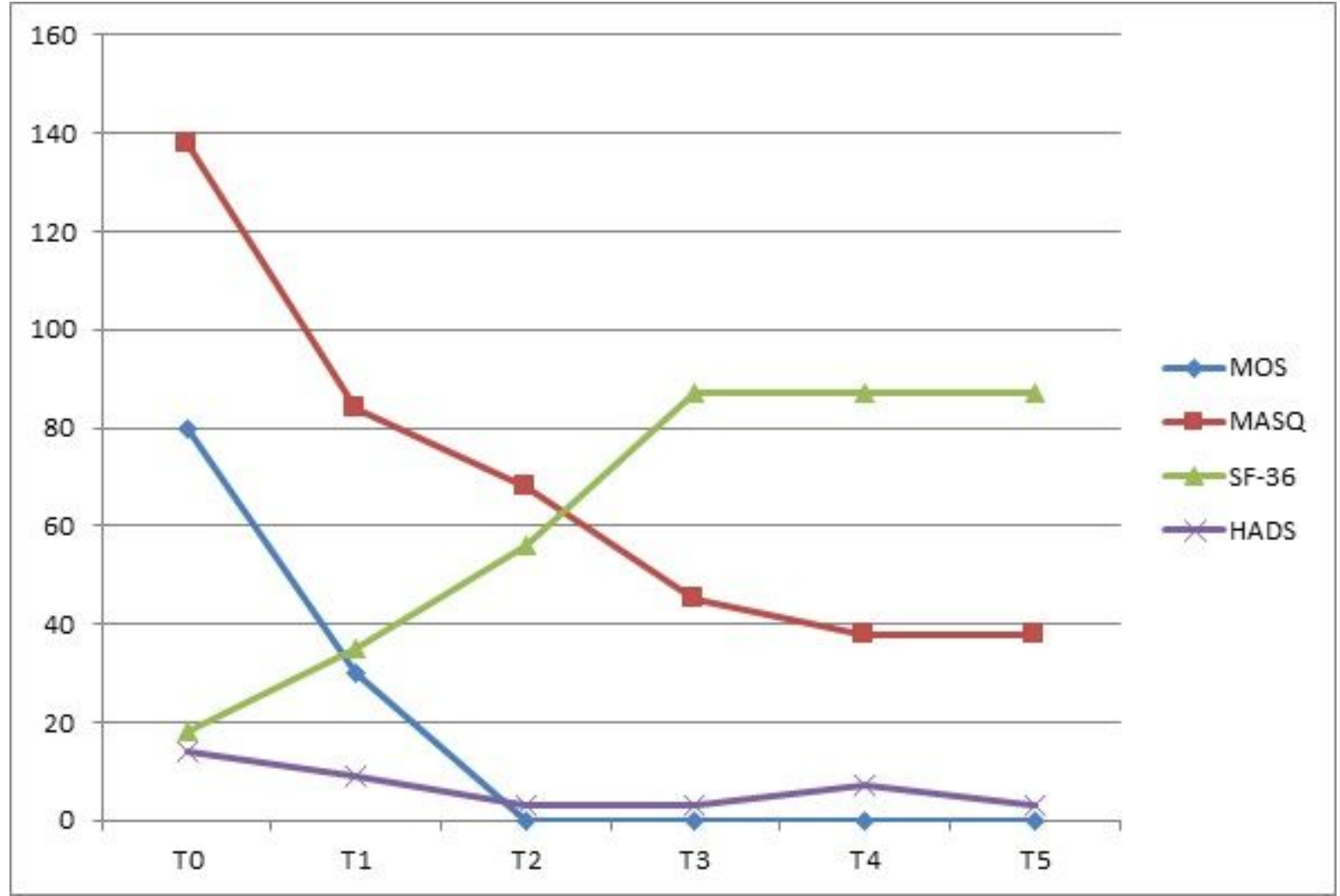

Figure 3 
Line graph showing trend in the outcomes (MOS, MASQ, SF-36 \& HADS) across timelines

\section{Supplementary Files}

This is a list of supplementary files associated with this preprint. Click to download.

- AIMEDHIGHLIGHTS.pdf 